\title{
ANÁLISE DE CONFLITOS E DO PROCESSO DECISÓRIO: SIMULAÇÃO DO GABINETE DE CRISES
}

\author{
Graciela Conti Pagliari ${ }^{1}$
}

Gabriel Mendes²

\section{Resumo}

O objetivo do trabalho é contribuir para a discussão sobre a utilização de metodologia pedagógica ativa, sobretudo, através de exercícios de simulação em sala de aula. No trabalho explora-se a aplicabilidade das simulações associadas à formação teórica em sala, o formato em que a atividade pode se desenvolver e a integração do exercício na avaliação acadêmica do estudante. $O$ trabalho tem como base as experiências de simulações do Gabinete de Crises da Presidência da Repúblicano curso de graduação em Relações Internacionais da Universidade Federal de Santa Catarina. Os resultados observados permitiram a implantação da atividade na estrutura da disciplina em que foi realizada e apontaram que a didática ativa complementa a teoria e a enriquece por meio da sua instrumentalização.

Palavras-chave: Relações Internacionais. Simulação. Gabinete de Crises.

\begin{abstract}
The article's aim is to contribute to the discussion on the use of active pedagogical methodology, especially through simulation exercises in the classroom. The article explores the applicability of the simulations associated with theoretical education, the format in which the activity can be developed and the integration of the exercise in the student academic evaluation. The article is based on the experiences of the "Crisis Cabinet of the Presidency of the Republic" simulations in the graduation degree in International Relations from the Federal University of Santa Catarina. The results allowed the implementation of the activity in the structure of the course in which it was performed and showed that the active didactic complements and enriches theory through its instrumentalization.
\end{abstract}

Keywords: International Relations. Simulation. Crisis Cabinet.

\footnotetext{
${ }^{1}$ Professora Adjunta da Universidade Federal de Santa Catarina/UFSC, pesquisadora do Laboratório de Estudos de Defesa (LED) e Grupo de Estudos em Segurança e Defesa (GESED). Email: graciela.pagliari@gmail.com.

2 Graduando em Relações Internacionais na Universidade Federal de Santa Catarina (UFSC), integrante do Oirã Grupo de Pesquisa e Extensão em Cooperação Regional na América Latina e bolsista pesquisador de Iniciação Científica do CNPq. Email: gab.mendes3@gmail.com
} 
99 | InterAção

\section{INTRODUÇÃO}

A incorporação do exercício de simulação do Gabinete de Crises na disciplina de Segurança Internacional do quarto semestre do currículo regular de Relações Internacionais na Universidade Federal de Santa Catarina (UFSC) ocorreu com o objetivo de ajudar a sanar uma deficiência que foi observada e discutida por graduandos no término da graduação em Relações Internacionais, egressos e professores do curso: um déficit de instrumentalização do conteúdo apreendido pelo estudante. A preeminência do aprendizado teórico é esperada de um curso circunscrito às Ciências Humanas. Relações Internacionais, assim como suas disciplinas afins, Direito, História e Ciências Políticas, por exemplo, possui como eixo central teorias que lhe dão forma e conduzem o seu desenvolvimento. No entanto, a exclusividade metodológica da utilização de textos para a formação acadêmica do profissional de Relações Internacionais esmorece o estudante do curso, que normalmente é composto por pessoas criativas, proativas e dinâmicas.

A carência de instrumentalização do conhecimento identificada no curso é uma observação mais característica dos professores, porém também compartilhada pelos discentes. Os estudantes possuem dificuldades em fazer a conexão da teoria com a prática, isto é, dificuldade em aplicar a teoria estudada em sala de aula na análise de casos práticos. Essa lacuna do aprendizado se reflete em uma das principais demandas do estudante de RI - uma formação profissional que o prepare para o mercado de trabalho -, uma vez que esta é a principal habilidade requerida por um analista de relações internacionais.

A pedagogia ativa, ou método de aprendizagem ativo, busca promover a interação, curiosidade e criatividade dos estudantes. Seus objetivos pedagógicos 
abarcam aumentar o interesse dos estudantes pelo objeto de estudo, transmitir a teoria das disciplinas com o reforço da atividade empírica e formar as capacidades dos futuros profissionais de Relações Internacionais: capacidade analítica, decisória e de negociação (ROCHA; PALACIOS JUNIOR, 2015). Por esses motivos, a pedagogia ativa mostrou-se uma ferramenta relevante e promissora na tentativa de conectar o aprendizado teórico com a prática no estudo em Relações Internacionais.

As simulações são métodos de ensino ativo que possibilitam a instrumentalização do conhecimento, sendo utilizadas, inclusive, como instrumentos de cooperação em altos níveis decisórios no campo militar. A simulação é "uma metodologia de criação de uma representação artificial do sistema mundial real, a fim de manipular e explorar as propriedades desse sistema" (MARINHA DO BRASIL, 2016). Conforme Corrêa e Medeiros (2013), métodos diferenciados de ensino, como os exercícios de simulação, favorecem a proximidade dos sujeitos com seus objetos de estudo e permitem uma visão mais realista. Dessa forma,

as simulações servem à mobilização do aparato teórico de forma que o método distinto cria determinantes mais precisos para a formação dos atores em questão, mas também, permite uma apreciação de maior efeito para a investigação científica. (CORRÊA; MEDEIROS, 2013, p. 2).

O presente artigo tem como objetivo o relato e o compartilhamento de experiências no campo metodológico ativo dos exercícios de simulação, especificamente na graduação em Relações Internacionais. Para esse fim, foram realizadas e observadas de modo ensaístico quatro experimentos entre os semestres 2014/ 2 e 2016/1. A primeira parte do artigo apresenta o Gabinete de Crises da Presidência da República e os motivos pelos quais este órgão foi escolhido para o exercício de simulação em Relações Internacionais. A segunda parte descreve experiências da elaboração do exercício, de que maneiras ele 
101 InterAção

pode ser configurado e utilizado como forma de avaliação pelo discente, assim como demonstra a simulação em si, suas exigências e vantagens. As considerações finais indicam as razões notadas para o emprego da simulação como método de ensino e demais sugestões de sua aplicabilidade e discussão.

\section{GABINETE DE CRISES}

O militar José Alberto Cunha Couto e o diplomata José Antônio de Macedo Soares, Secretário e Secretário-Adjunto, respectivamente, da Secretaria de Acompanhamento e Estudos Institucionais (SAEI) do Gabinete de Segurança Institucional (GSI) da Presidência da República durante o período 1998-2011, descrevem, em seu livro de 2013, a implantação e o funcionamento do Gabinete de Crises no Brasil desde sua criação no governo Fernando Henrique Cardoso até o governo Dilma Rousseff. Os autores definem o Gabinete como um "um foro de articulação para temas com potencial de crise", mais especificamente, um centro de operações localizado na Presidência da República que acompanha meticulosamente todos os eventos internos e internacionais que apresentam potencial para gerar uma crise doméstica. A sua função, portanto, é instrumentalizar o Presidente da República para a tomada de decisão em situações complexas (COUTO; SOARES, 2013, pp. 37-9).

Nos quadros da SAEI estão oficiais militares do Exército, da Marinha e da Aeronáutica, agentes da Agência Brasileira de Inteligência (Abin) e diplomatas, além de advogados, engenheiros, delegados e gestores públicos. Civis e militares, desse modo, trabalham conjuntamente em uma equipe multissetorial no controle e observação de situações alarmantes. Ao se configurar um cenário de crise, o Presidente da República é imediatamente informado e a Presidência, por sua vez, aciona a instalação do Conselho de 
Defesa Nacional, ou Gabinete de Crises. Este órgão ad hoc é composto por 11 autoridades nacionais, além do Presidente da República: os Comandantes da Marinha, do Exército e da Força Aérea, o Chefe do Estado-Maior Conjunto das Forças Armadas, os Ministros do Planejamento, das Relações Exteriores, da Justiça e da Defesa, os Presidentes do Senado e da Câmara dos Deputados e o Vice-Presidente da República. Todas as autoridades se reúnem no mesmo local para aconselhar o Presidente da República na sua decisão (de agir ou não, e como proceder a ação), assessorados por todas as informações necessárias compiladas pelos funcionários da SAEI.

A simulação do Gabinete de Crises, portanto, coloca os estudantes de Relações Internacionais no lugar das autoridades nacionais reunidas para decidir uma ação que trará mudanças para o governo e a vida dos cidadãos do país. Os estudantes têm que assumir o posto de tomadores de decisão ou de cargos que irão influenciar seriamente a decisão final. Os cargos presentes no Conselho originam-se de diferentes áreas do cenário nacional de tomada de decisão, como a área militar (Comandantes das Forças Armadas), política (cargos eleitos), econômica (Ministro do Planejamento), diplomática (Ministros das Relações Exteriores e da Defesa), jurídica e social (Ministro da Justiça). Dessa maneira, os estudantes ensaiam os múltiplos campos de atuação do profissional de Relações Internacionais, ademais das habilidades de análise de casos empregadas na pesquisa e seleção das informações essenciais para a execução do Gabinete.

A ideia da aplicação do exercício de simulação do Gabinete de Crises da Presidência da República para fins de aprendizado não é pioneira. A Escola de Comando e Estado-Maior do Exército (ECEME), localizada na cidade do Rio de Janeiro, onde se desenvolvem os cursos de mais alto nível de capacitação do Exército Brasileiro, utiliza a prática da simulação como método de ensino e avaliação de seus estudantes militares e civis. Enquanto a simulação da ECEME 
prepara seus estudantes militares para executar papeis de liderança em níveis estratégicos, operacionais e táticos, a simulação do mesmo exercício nas Relações Internacionais teria como objetivo preparar os graduandos para o mercado de trabalho com uma combinação de capacidades práticas colocadas à prova (trabalho em equipe, análise de cenários) numa situação de pressão em que as ações praticadas terão consequências importantes, além de desempenhar a instrumentalização do conteúdo lecionado durante a graduação.

\section{EXERCÍCIO DE SIMULAÇÃO}

A fim de que o exercício de simulação se realize no final do semestre letivo, é importante que a preparação para a atividade dê início com meses de antecedência. Durante a preparação da simulação deve ser escolhido o tema a ser trabalhado no Gabinete de Crises, os grupos e os cargos devem ser divididos entre os estudantes, o Guia de apoio para o Gabinete deve ser formulado e o professor deve conceber as questões a serem respondidas pelos estudantes durante a simulação, cujo resultado será base para a avaliação do exercício.

\subsection{PREPARAÇÃO PARA O EXERCíCIO}

Porém, antes de delegar as funções, deve-se efetuar um primeiro contato do Gabinete com os estudantes, para melhor prepará-los. O livro de Couto e Soares (2013) é a opção considerada mais adequada. Nele, o Gabinete de Crises tem sua estrutura e seu funcionamento explicados detalhadamente pelos 
autores fundadores do órgão no Brasil, na década de 1990. É sugerida a leitura pelos estudantes e uma discussão posterior em sala de aula dos capítulos 3, 4 e 5, respectivamente: A Estrutura de um Gabinete de Crises; Processo Decisório e Tomada de Decisão em Alto Nível e; A Dimensão Internacional das Crises; a escala mínima de acompanhamento de temas. A integralidade do livro deve ser recomendada para um conhecimento mais profundo sobre o Gabinete. Os seus capítulos iniciais descrevem os motivos pelos quais se devem a existência de um órgão como esse na Presidência da República e os capítulos subsequentes trazem aprendizados ricos contendo exemplos de situações reais de crises que moldaram o formato do Gabinete. O artigo de Couto (2003) intitulado O Gabinete de Segurança Institucional: o gerenciamento de crises traz a definição da crise e traça as principais características funcionais do Gabinete. Por fim, o artigo de Trindade e Farah (2010) oferece maneiras para lidar com uma situação de crise no Gabinete trazendo valiosas lições.

Após o primeiro contato dos estudantes com o Gabinete, recomenda-se a escolha do tema que será apreciado durante a simulação. Em vista de que o exercício foi implementado na disciplina de Segurança Internacional, concordamos que o tema escolhido deveria trazer uma dimensão de Segurança, Defesa e Geopolítica, ao mesmo tempo em que deveria inserir o componente internacional, ou seja, abarcar outros Estados. Dentre os temas já utilizados no exercício estão o conflito diplomático Colômbia-Equador de 2008, resultante da invasão territorial do exército colombiano no país vizinho para assassinar Raúl Reyes, número dois das Forças Armadas Revolucionárias da Colômbia (FARC); a instalação de bases norte-americanas na Colômbia em 2009 e; o conflito diplomático Colômbia-Venezuela de 2015, acerca da crise fronteiriça entre os dois países. Como nota-se, há uma predileção por casos sul-americanos, dada a importância do contexto de inserção regional do Brasil, evidenciada na Estratégia Nacional de Defesa (BRASIL, 2008). 
Entre as alternativas de um caso passado, com término observado e um caso atual, ainda em curso, pesam-se vantagens e desvantagens. No primeiro caso, o exercício é mais controlado com poucas chances de erro, no entanto, também se torna mais previsível, na medida em que a sua conclusão é publicamente conhecida. Enquanto no caso em andamento, não se tem conhecimento de todas as variáveis, mas os estudantes demonstram mais interesse, uma vez que a grande mídia está noticiando o seu desenvolvimento e o seu desfecho é desconhecido, permitindo maior uso da imaginação pelos estudantes. Pensou-se em deixar a escolha final do tema com os próprios estudantes, almejando que a escolha do tema que mais lhes interessam aumente a dedicação no desenvolvimento da elaboração do exercício.

Nas divisões de grupos e cargos, contudo, perceberam-se mais proveitos nos semestres em que os estudantes não as fizeram de livre arbítrio. A organização dos grupos pela afinidade entre os estudantes os permite a comodidade de trabalhar com pessoas de pensamentos semelhantes ou próximos, impedindo o processo natural de trabalho em equipe com indivíduos que agem e pensam de forma diferente, como ocorre em qualquer área profissional. Da mesma maneira, a disposição dos cargos pelos próprios estudantes faz com que eles selecionem papéis confortáveis às suas habilidades e mesmo às suas personalidades, não deixando espaço para um momento de readequação e adaptação a novos desafios, tão recorrentes na carreira de um internacionalista. Em muitos momentos da simulação, um estudante de caráter essencialmente pacífico deve aconselhar uma intervenção militar em outro país, pois está exercendo o cargo de Comandante das Forças Aéreas, por exemplo. Em outros, um estudante impaciente e pragmático deve controlar-se e sugerir uma solução diplomática, já que exerce o cargo de Ministro das Relações Exteriores. A adaptação ao cargo no exercício é uma das características mais 
estimulantes e pertinentes para a preparação dos estudantes ao mercado de trabalho.

Para tal, são realizados sorteios. Conforme o número de estudantes matriculados na disciplina, são arranjados grupos de 12 participantes, o número de autoridades membros do Gabinete de Crises. ${ }^{3}$ No mesmo momento, são sorteados os cargos dos participantes de cada grupo. É de extrema importância que cada estudante saiba as funções exercidas pelo seu cargo no Gabinete de Crises, viabilizando a condução do exercício de forma satisfatória.

A etapa mais importante da fase de preparação para o exercício é a confecção do Guia de Estudos sobre o objeto do Gabinete de Crises. Também é a etapa que mais apresenta dificuldades de produção e organização. O objetivo fundamental do Guia é nivelar o conhecimento de todos os participantes da simulação acerca do caso em exame. Trata-se de um trabalho escrito que deve conter um estudo da crise em questão, com a apresentação do problema, panorama histórico situando antecedentes e origens da crise, assim como as relações entre os países envolvidos a respeito da situação e o envolvimento do Brasil na questão, isto é, o que está em jogo para o país. O Guia deve compreender dados abrangentes e específicos de origem social, militar e diplomática, bem como gráficos e mapas que facilitem a assimilação de informações relativas à crise. Em síntese, o Guia substitui a compilação de dados e informações que os funcionários da SAEI realizam diariamente no GSI da Presidência da República e apresentam às autoridades nacionais membros do Gabinete de Crises, que por sua vez, absorvem o conteúdo, proporcionando melhor atuação na solução da crise.

\footnotetext{
3 Caso o número não seja propício, fazem-se grupos de 11, excluindo, assim, o cargo de Chefe do Estado-Maior Conjunto das Forças Armadas (redistribuindo suas funções aos três Comandantes das Forças Armadas). Ou ainda, grupos de 10 participantes, excluindo também o Vice-Presidente (suas funções são acumuladas, facilmente, pelo Presidente).
} 
Na maioria das experiências, a elaboração do Guia de Estudos ficou sob responsabilidade de todos os estudantes da disciplina, que dividem os conteúdos entre si para simplificar a produção do texto. Esse formato sempre apresentou problemas de execução, seja porque a produção conjunta não atinja um resultado harmônico, seja porque parte dos estudantes ausenta-se do esforço em equipe, o que assinala uma avaliação desproporcional do processo. Em um semestre, o Guia de Estudos foi completamente fornecido aos estudantes, trabalho fruto da bolsa científica relacionada à produção deste artigo. De forma esperada, neste caso, não houve contratempos ou obstáculos. Por sua vez, este método isenta aos estudantes a oportunidade de análise casual e temporal de crises, ao mesmo tempo em que os priva desta parcela da avaliação. Outras sugestões de organização são a produção de um Guia de Estudos por cada grupo do exercício, aderindo à avaliação em equipe da simulação, ou a pesquisa individual por cada participante, cujo resultado seria contemplado na sua participação da simulação.

A última parte da preparação, a formulação das questões a serem respondidas durante o exercício, cabe ao professor. A relação de questões será entregue aos estudantes somente ao início da simulação. Uma das principais preocupações nesse item do processo é a adequação das questões com o tempo predeterminado de duração da simulação do Gabinete. No tempo limite do exercício, cada grupo deve discutir a crise instalada, suas possíveis consequências e soluções e responder às questões formuladas pelo professor. Dessa maneira, recomenda-se a proposição de duas ou três questões. É interessante que elas sejam específicas, evitando generalizações nas futuras respostas, pois o intuito é avaliar o direto posicionamento assumido pelos participantes. Uma das questões sempre costuma abordar a realização de um pronunciamento do governo brasileiro acerca da crise e o conteúdo da possível mensagem. As demais questões costumam englobar o posicionamento e as 
possíveis ações do governo brasileiro nos âmbitos das organizações multilaterais envolvidas no caso e na região e de uma possível cooperação militar do Brasil com outro(s) país(es) almejando o fim da crise. Outro aspecto importante é insinuar a formulação de uma ação por parte do governo brasileiro. Afinal de contas, as autoridades nacionais foram reunidas com o propósito de delinear o cumprimento de uma ação prática, seja ela diplomática, militar, econômica ou social.

Por fim, coloca-se como sugestão a confecção de situações particulares a serem distribuídas para os grupos durante o desenvolvimento da atividade. Estas situações, ou problematizações, seriam acontecimentos de natureza fictícia, simultâneos à execução das atividades do Gabinete de Crises. As dinâmicas de cada grupo se engrenam de modo diverso, de tal forma que alguns tendem a finalizar a discussão e as propostas de solução em um tempo inferior ao determinado, enquanto outros podem se estender além do tempo desejado em cada questão. As situações particulares fictícias, dessa maneira, tentam harmonizar a duração do exercício para todos os grupos, ao movimentar as discussões. A ideia nessa proposta opcional é de que cada grupo receba uma problematização diferente, seja uma movimentação militar nas fronteiras, um discurso enviesado de um chefe de Estado, ou um vazamento de informação confidencial. A adição dos acontecimentos simultâneos enriquece o teor da avaliação e da discussão final após a simulação.

\subsection{PRÁTICA DO EXERCÍCIO}

Com o Guia de Estudos concluído e sua leitura realizada por todos os participantes, é possibilitada a execução do exercício de simulação do Gabinete de Crises. O dia de simulação é composto por três partes, em que cada uma 
possui duração de aproximadamente 1 hora. Na primeira parte do dia acontece uma apresentação do Gabinete do ponto de vista militar com um convidado palestrante. Após a exposição do palestrante efetua-se, de fato, a realização do exercício de simulação do Gabinete. E por último, ocorre a discussão final sobre o exercício e os resultados de cada grupo.

A palestra, ou conversa expositiva, é um recurso discricionário que promove a inserção dos participantes do exercício na dinâmica funcional de um Gabinete de Crises. Felizmente, os corpos docente e discente da ECEME do Rio de Janeiro sempre se mostraram solícitos às nossas requisições de palestras, na sua condição de disponibilidade. Igualmente, o Major Rodrigo Antônio Silveira dos Santos, Prefeito da Aeronáutica de Florianópolis e Professor da Universidade da Força Aérea, nos auxilia continuamente com a prática da simulação. O imprescindível, no entanto, é que todos os participantes estejam conscientizados das funções do cargo que irão representar no Gabinete.

A segunda parte do dia de simulação é o exercício em si. Antes mesmo de iniciarem os trabalhos do Gabinete de Crises, os grupos estarão sendo avaliados pela preparação do ambiente em que a atividade se dará. A organização dos lugares, por exemplo, é fundamental para o bom desenrolar das discussões. O formato ideal é o de mesa em "U", cujo vértice é ocupado pelo Presidente da República, enfatizando o processo de articulação e não de direção ou coordenação (COUTO; SOARES, 2013, p. 60). Recursos de mídia são opcionais, uma vez que os grupos são encorajados a trazerem mapas, computadores e demais dispositivos visuais. É interessante também que cada grupo se instale em uma sala exclusiva, de modo a não ser perturbado pelas discussões dos demais grupos.

Ao início do exercício, as questões a serem respondidas pelos grupos em cada Gabinete são entregues aos participantes. A partir desse momento, os 
grupos se tornam independentes de qualquer auxílio do professor. Os trabalhos do Gabinete são conduzidos exclusivamente pelo participante representando o Presidente da República, assim como é dele a definição do formato das discussões e a responsabilidade pelas soluções defendidas. No decurso da simulação, o professor, o convidado palestrante e outros possíveis convidados (bolsistas, mestrandos, etc...) transitam entre as salas para acompanhar o desenvolvimento do Gabinete sem praticarem intervenções. Passada metade do tempo determinado da duração do exercício, e caso os grupos estejam se direcionando para a resolução das questões, é o momento ideal para a entrega das situações particulares fictícias, se o professor tenha as considerado convenientes.

Encerrado o exercício de simulação, todos os participantes retornam à mesma sala de aula para a leitura e discussão dos resultados definidos pelos grupos. Ao efetuar a leitura das posições defendidas pelo grupo, um participante representante deve também destacar os motivos pelos quais o grupo decidiu por tais soluções, demais alternativas que foram suscitadas, a razão pela desconsideração destas e, se for o caso, explicar a situação particular fictícia a qual o grupo tenha sido exposto e de que maneira ela alterou o posicionamento final do Presidente da República.

No processo de discussão dos resultados, o professor e os convidados a participarem do exercício devem analisar, julgar e criticar as soluções defendidas por cada grupo e provocar os estudantes a pensarem suas ações no Gabinete de Crises de acordo com o conteúdo teórico apreendido durante o semestre letivo. A repercussão desejada é que os estudantes compreendam que as ações por eles deliberadas possuem consequências concretas e diretas na eficiência do governo, no posicionamento internacional do Estado brasileiro e na vida das populações afetadas pela situação de crise. 
111 InterAção

A discussão final e a avaliação possuem dois pontos centrais e indispensáveis. O primeiro é a decisão do grupo de divulgar algum comunicado para a imprensa e o teor do conteúdo da suposta nota pública. É essencial que os estudantes entendam a importância e a gravidade das dimensões de interpretação do conteúdo de uma mensagem. O outro ponto, finalmente, trata-se da solução proposta, isto é, a ação decretada pelo Gabinete de Crises. Não basta que a solução seja apenas viável, realística e de acordo com os compromissos e princípios assumidos pelo Brasil, além disso, é vital que tal ação resguarde os interesses do país nos cenários regional e internacional, tanto no curto como no longo prazo.

O formato da avaliação final possui uma alternativa às questões propostas pelo professor. Ao invés de indicar uma ação a ser realizada, o grupo pode ser instruído a construir cenários prospectivos tendo em vista a crise instalada. A prospecção de cenários é uma área estimulante e pertinente dentro da metodologia pedagógica ativa de simulação, em que os estudantes, nesse caso, são responsáveis por elaborar, em média, três cenários de médio prazo, considerando as variáveis integradas à situação de crise, que retratam três possíveis quadros resultantes: um desfavorável, um mais favorável e outro que se configura no meio-termo dos extremos. Para um contato mais profundo com a prospecção de cenários é recomendada a leitura do livro de 2014, Do Eldorado à Selva: Cenários da Integração Sul-Americana até 2030, de autoria do Grupo de Elaboração de Cenários Prospectivos da Universidade Estadual Paulista (UNESP), coordenado pelo Professor Samuel Alves Soares. 
112 InterAção

\section{CONSIDERAÇÕES FINAIS}

As quatro experiências de aplicação do exercício de simulação do Gabinete de Crises demonstraram-se férteis e renderam algumas considerações sobre sua incorporação à metodologia de ensino nas Relações Internacionais. Embora nem todos os semestres tenham tido sucesso em cada aspecto do exercício, a sua contínua aplicação permitiu avanços logísticos, e também pedagógicos. A estratégia "erro e acerto" parece a mais propícia quando a bibliografia sobre a área não se prova suficiente para sanar os momentos de dúvida afrontados.

Como característica de avaliação, o exercício teve sua importância aumentada conforme a subsequência de semestres, isto é, o peso de sua avaliação cresceu na composição da média final dos estudantes, até receber o peso de um exame escrito. Isso permitiu aos estudantes a adaptação de forma gradual da inclusão da prática do Gabinete de Crises em seus planejamentos acadêmicos semestrais e no curso de graduação em Relações Internacionais da UFSC de forma geral. A avaliação final contém a produção do Guia de Estudos, a postura dos participantes durante a simulação e a adaptação aos cargos, as propostas de solução dos grupos junto a qualquer documento escrito produzido e, também, a participação dos grupos na discussão final após a simulação do Gabinete.

A disciplina de Segurança Internacional na graduação da UFSC encontra-se no quarto semestre, portanto, na metade da duração do curso. Dessa forma, o mérito da aplicação do exercício só aumenta, na medida em que ele possibilita aos estudantes um contato com a atuação profissional do internacionalista, diverso da diplomacia tradicional do Itamaraty. É notório que nenhum recente egresso de Relações Internacionais irá compor a mesa de 
113 InterAção

autoridades do Conselho de Defesa Nacional. Contudo, as capacidades desenvolvidas durante a preparação e a aplicação do exercício são as mesmas as quais os internacionalistas utilizam na sua prática profissional, seja qual for sua área de atuação. A análise de casos, o trabalho em equipe com profissionais de outros campos de estudo, a redação de documentos e pronunciamentos, a tomada de posições e decisões e a prospecção de cenários, são todas capacidades exigidas do futuro profissional de Relações Internacionais, além dos seus conhecimentos teóricos.

Quando perguntados sobre a participação no exercício de simulação, os estudantes manifestam empolgação, majoritariamente. Eles dão-se conta, finalmente, da atuação de um internacionalista no campo prático, expressando que conseguem colocar em ação o vasto catálogo teórico armazenado desde o primeiro semestre da graduação. Os estudantes encorajam pela continuação do exercício no curso e mesmo a adição de mais métodos ativos de ensino. Essa experiência demonstrou que o uso da pedagogia ativa, portanto, seja por meio de simulações, estudos de caso, jogos, textos alternativos, role-play ou utilizando recursos tecnológicos, auxilia, de fato, a instrumentalização do conteúdo pelos estudantes.

O objetivo deste artigo e do trabalho de acompanhamento da aplicação do exercício durante os dois últimos anos foi de contribuir com a construção do conhecimento sobre métodos ativos de ensino nas Relações Internacionais, agregando de alguma maneira o empenho para discutir o ensino na área. É de excepcional importância a realização de mais relatos e mais compartilhamentos de experiências que incrementam o aprimoramento e o progresso do estudo de Relações Internacionais. 


\section{REFERÊNCIAS}

BRASIL (Estado). Constituição (2008). Decreto $n^{\circ}$ 6.703, de 18 de dezembro de 2008. Estratégia Nacional de Defesa. Disponível em:

<http://www.planalto.gov.br/ccivil_03/_ato2007-

2010/2008/Decreto/D6703.htm>. Acesso em: 18 jul. 2016.

CORREAA, Claudio Rodrigues; MEDEIROS, Sabrina Evangelista. Jogos e

Cenários: Simulações em Benefício da Defesa. 2013.

COUTO, José Alberto Cunha. O Gabinete de Segurança Institucional: o gerenciamento de crises. In: Congreso Internacional del CLAD sobre la Reforma del Estado y de la Administración Pública, 8, 2003, Panamá. Disponível em: <http://unpan1.un.org/intradoc/groups/public/documents/CLAD/clad0047 338.pdf>. Acesso em: 18 jul. 2016.

COUTO, José Alberto Cunha; SOARES, José Antônio de Macedo. Gabinete de Crises: Fernando Henrique, Lula e Dilma. Campinas: Facamp, 2013.

GRUPO DE ELABORAÇÂO DE CENÁRIOS PROSPECTIVOS. Do Eldorado à Selva: Cenários da Integração Sul-Americana até 2030. São Paulo: Editora Unesp, 2014.

MARINHA DO BRASIL. Laboratório de Simulações e Cenários. Simulações, Cenários e Jogos de Guerra: abordagens teóricas. Disponível em:

<https:// www1.mar.mil.br/simulacoesecenarios/simulações-cenários-e-jogosde-guerra---abordagens-teóricas>. Acesso em: 15 jul. 2016.

ROCHA, Raquel Maria de Almeida; PALACIOS JUNIOR, Alberto Montoya Correa. As Simulações como Instrumento Pedagógico em RI: aplicação de exercício transdisciplinar em Análise de Processo Decisório e Geopolítica. Belo Horizonte: 2015.

TRINDADE, Marcos da Costa; FARAH, Miriam Medeiros de Godoy. Gabinete de crises. In: CONGRESSO CONSAD DE GESTÃO PÚBLICA, 3, 2010, Brasília. Disponível em: <http://banco.consad.org.br/handle/123456789/231>. Acesso em: 18 jul. 2016. 